\title{
Digital platforms for managing transport and logistics systems in the context of sustainable development
}

\author{
Aleksandr Dmitriev* and Irina Plastunyak \\ Sankt-Petersburg State University of Economics, Sadovaya street, 21, 191023 St. Petersburg, Russia
}

\begin{abstract}
The article discusses the development of transport and logistics systems based on integrated digital platforms, discusses the logistics of sustainable development based on the use of modern digital technologies. The article analyzes modern global initiatives in the field of "green" logistics, which have a significant impact on the efficiency and competitiveness of supply chains. Digital platforms that play a key role as system integrators of sustainable development in logistics are studied, and a forecast of their use in the EEU space is provided. A model of an integrated transport and logistics system based on interaction, competition, collaboration and cooperation has been formed.
\end{abstract}

\section{Introduction}

Worldwide interest in environmental protection and acquisition of environmentally friendly products ("green" concept) is becoming more and more popular. At the state level, a number of countries, efforts continue to develop the most common legal framework designed to protect the environment. Manufacturers understand how important it is to ensure the availability of environmentally friendly products on store shelves. To do this, they begin to use the so-called "green" practices. This concept is based on a sustainable approach to the development of society, which is based on several components, the idea of implementing the requirements of modern society without compromising the ability of future generations [1]. Green logistics examines the impact of product distribution processes on the environment [2] and is considered as the basis of ecological survival [3].

"Green" logistics or eco-logistics in this context is a specific set of initiatives and measures designed to eliminate negative environmental impacts caused by the activities of enterprises in the transport and logistics industry. This concept of logistics influences the configuration of processes, structures, logistics systems and the characteristics of equipment used in the transport, distribution and storage of goods.

The traditional approach to logistics often leaves environmental sustainability issues aside in decision making. On the other hand, the goal of green logistics is to find a balance between ecology and economy. This article analyzes the main issues related to improving the efficiency and sustainability of transport and logistics systems.

${ }^{*}$ Corresponding author: poliskasko@bk.ru 
The main goals and objectives of the "green" reengineering of transport and logistics systems include:

- assessing the negative impact of logistics operations in supply chains to establish a starting point for considering sustainability measures and monitoring their results. One of the most common methods for calculating energy consumption and greenhouse gas emissions is international environmental safety standards;

- development of measures to reduce air, soil, water and noise pollution by analyzing the negative impact of each functional area of logistics, primarily related to transport;

- rational use of consumables, reuse of returnable pallet, containers and recycling of packaging;

- ensuring the sustainability of the supply chain and environmentally friendly logistics through the use of special designs for finished products and transport packaging, which must be designed to minimize negative impact on the environment.

Implementing the concept of sustainability in transport and logistics systems, it is necessary to find effective, economically viable solutions that reduce the dependence of the transport sector on the conjuncture of the fuel markets when organizing freight traffic, increase the efficiency of loading rolling stock, improve the characteristics of logistics infrastructure facilities, contribute to the growth of investments in upgrading material and technical bases and automation of transport and logistics business processes, increasing the transparency and reliability of the functioning of transport and logistics systems, including for consumers.

At the same time, much attention is paid to digital technologies, which were initially considered only as a paperless document flow, and now, within the framework of "green" logistics, this is a comprehensive reduction of the environmental burden on the environment, primarily within the framework of management of transport and logistics systems [3].

\section{Methods for analyzing the effect of implementing a digital platform}

Environmental sustainability has received considerable attention in industry and academia. Many firms have begun to adopt sustainability practices, such as investing in cleaner technology and using organic or recyclable materials, to enhance sustainability in supply chains [4].

While SCM is a well-established field of research looking for instance at transportation, network management, or demand planning, this is less the case of sustainable supply chain management (SSCM). In this sense, SSCM can be defined according to Seuring and Müller $(2008$, p.1700) as: "The management of material, information and capital flows as well as cooperation among companies along the supply chain while taking goals from all three dimensions of sustainable development, i.e., economic, environmental and social, into account which are derived from customer and stakeholder requirements" [5, 6].

Global supply chains power $80 \%$ of world trade, but also host widespread environmental, labor, and human rights abuses in developing countries. The result is a supply chain that is more efficient, more humane, and embeds sustainability in the supply chain for the long-term [7]. Sustainability and digitalization have become the main direction of transformation of enterprises. Building a digital twin platform network can provide enterprises with a comprehensive view of products, manufacture, supply chain, customer experience, and profitability, which is conducive to the construction of a sustainable business model [8].

Recently there have been signs of greater synergies between sustainability and supply chain management and some publications now suggest that the sustainable supply chain 
management literature is beginning to link with current thinking in sustainability and transport and logistics business [9]. The sustainable development concept has become a key basis to create the transport infrastructure and material supply systems in cities. As a result of the experiment, it has been established that with an increase in the vehicle load-carrying capacity, the cumulative negative impact of the supply chain decreases [10].

Now the focus has turned on development of circular economy, which provides the efficiency of material and energy. Digitalization gives new opportunities for improving the use of disposed materials [11]. Using some digital instruments such as TradeCloud IT platform a focal company is connected to its suppliers and customers. Through this platform information, goods and money flows in the supply chain are managed [12].

The key promises of fourth industrial revolution, named "Industry 4.0" concept are enabling real-time full-transparency from suppliers to customers, small lot sizes, multiple product variants, connected processes and decentralized, autonomous management [13]. Data as a resource and data sharing enable competitive supply chains and present-day digital platform business models. The recipe for these competitive supply chains will no longer be contingent on how different companies contract to share data in their existing business networks but how these companies make these contracts available for the others in multi-sided markets [14].

Digital platforms are an omnipresent phenomenon that challenges incumbents by changing how we consume and provide digital products and services. Whereas traditional firms create value within the boundaries of a company or a supply chain, digital platforms utilize an ecosystem of autonomous agents to co-create value [15].

In [16] the processes of structural transformation and network convergence of regional information spaces are considered. The importance of deploying an integrated digital platform within a separate state, and later, given the trend of erasing information borders between countries, and international integrated platforms is noted. In this regard, mention is made of the study of the Center for Strategic Research "State as a Platform" [11], in which citizens and businesses are considered as the main recipients of public services in electronic form, and all users operate with common databases with different levels of access. At the same time, additional synergistic effect for business is achieved by applying advanced methods of network interaction, management of network behavior, as well as "through hypercompetitive creative neuromarketing, management, logistics, etc." [11, p. 1198].

As for the Eurasian Economic Space, the results of the conducted research also indicate significant digital dividends in the transformation of the service sector [17, p. 3] (fig. 1).

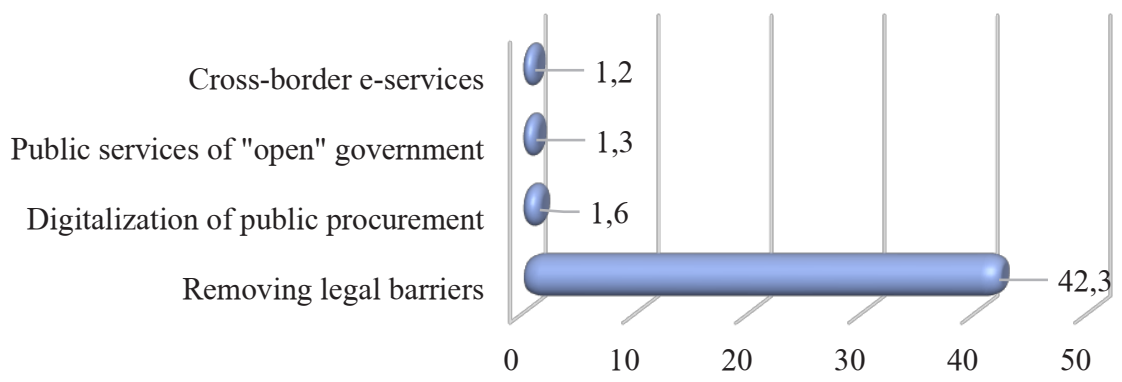

Fig. 1. Digital dividends from the implementation of the EAEU digital agenda from 2025, USD billion [17, p. 3].

Thus, the most important is the formation of such a platform that eliminates legal barriers, it was also proved in [15] that electronic logistics is a key factor in the growth of the country's economy, and the most important indicators that determine customer 
satisfaction with logistics services are the minimum delivery time and delivery, efficient payment methods and the use of information technology.

\section{Results and discussion of the theoretical model of the digital platform}

The introduction of modern digital technologies through the visibility of supply chains may be a solution to this problem, including integrated transport and logistics systems visibility at all goods delivery stages from manufacturers to end users (fig. 2).

Federal Government, Ministries and Departments, regional ministries, departments, committees, administrations, municipal administration, departments of the consumer market, transport and communications, foreign economic activity, industry-forming enterprises and natural monopolies, management of railway departments, administration of river and sea ports, regional customs management ("Digital customs")

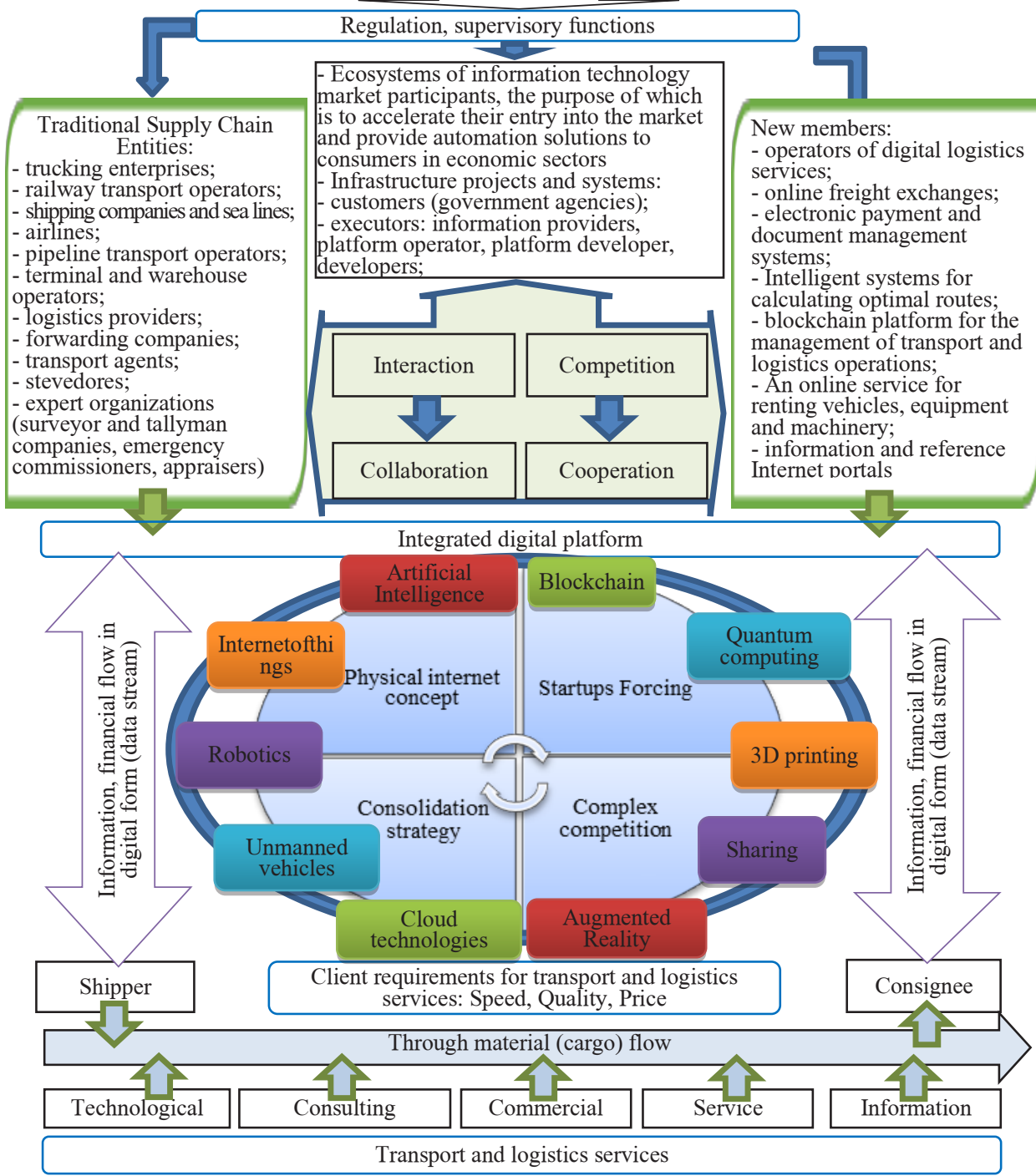

Fig. 2. Digitalization of integrated transport and logistics systems. 
At the same time, an increase in the efficiency of the functioning of transport and logistics systems should be considered through the prism of the introduction of integrated digital platforms, which are the focal link and information and analytical core of supply chains, uniting all participants at various levels of management of the processes of goods movement.

However, it should be recognized that at present the transport and logistics industry is not distinguished by a high degree of stability. Companies face significant obstacles in the implementation of environmental policy in the field of logistics, which is primarily due to the insufficient level of formation of integrated digital platforms, interaction with government agencies, and for international supply chains - with customs authorities. In this regard, it should be noted such a project as "digital" customs, which is being actively implemented by the FCS of Russia. The use of digital seals allows for continuous tracking of goods and the introduction of "electronic" transit, and the experiment with an electronic waybill will reduce and even completely eliminate the possibility of delivering goods to an unauthorized person.

It is important to note that a significant condition for improving the efficiency of modern transport and logistics systems is currently reducing the negative impact of transport on the environment in the logistics chain. This can be achieved not only through the application of higher environmental standards that limit emissions, but also through the use of modern digital technologies and logistics information systems that help manage orders, plan delivery routes, and prioritize load distribution on vehicles. [18].

In addition, in their logistics practice, enterprises need to widely use modern information systems for electronic document management and data exchange in order to increase their competitiveness in the transport and logistics market.

\section{Conclusions}

New digital information technologies are forcing more and more companies to use these technologies as factors to improve efficiency and reduce production and service costs. The demand for the introduction of new methods and technologies increases as innovation attracts new customers. This gives businesses an additional competitive edge. [19].

In particular, intermodal transport and logistics systems achieve high performance due to the introduction of new forms of information and communication interaction between various links of the transport and logistics chain, including state control bodies. And one of the key criteria for the effectiveness of such systems is the degree of digitalization of their business processes.

Thus, if supply chain management activities are carried out in accordance with government regulations and meet customer expectations, transport and logistics companies have an incentive to develop green practices. The "green" movement is not only thinking, company image, strategy, but also a factor in the success of supply chains.

\section{References}

1. A. Dmitriev, ESTIEM Magazine, 44(1), 52 (2013)

2. L.Y. Berezhnaya, Logictics and Supply Chain Management, 2 (85), 52 (2018)

3. Nikita A. Osintsev, Alexander N. Rakhmangulov, Vera V. Baginova, Mir Transporta (World Of Transport And Transportation) Journal, 2 (75), 196 (2018)

4. C. Dong, Q.Li, B. Shen, X. Tong, Sustainability, 11, 4071 (2019) 
5. M.M.C. Fritz, Sustainable Supply Chain Management. Responsible Consumption and Production. Encyclopedia of the UN Sustainable Development Goals (2019)

6. S. Seuring S, M.Müller, J Clean Prod, 15(7), 69 (2007)

7. Robert C. Bird, Vivek Soundararajan,. From Suspicion to Sustainability in Global Supply Chains, 7, 383(2020)

8. X. Li, J.Cao, Z. Liu, X.Luo, Sustainability, 12(3), 1 (2020)

9. P.Nieuwenhuis, A.Touboulic, L. Matthews, Is Sustainable Supply Chain Management Sustainable? In Sustainable Development Goals and Sustainable Supply Chains in the Post-Global Economy, 13 (2019)

10. A.Rossolov, O.Lobashov, D. Kopytkov, V. Naumov, Transportation Research Procedia, 45, 795 (2020)

11. V. Salminen, H. Ruohomaa, T. Pöykkö, 2016 International conference on production research - Africa, Europe and the Middle East and 4th International conference on quality and innovation in engineering and management (2020)

12. Jan H Jansen, Elena Kaledinova, Ann Wolter, Integration of a supply chain through the TradeCloud IT platform. Projects: IT platforms in Supply Chain FinanceCase study Supply Chain Finance: IT platform for SMEs, (2020)

13. Y. Kayikci, Procedia Manufacturing, 21, 782 (2018)

14. H.Huttunen, T. Seppala, I. Lahteenmaki, J. Mattila, What Are the Benefits of Data Sharing? Uniting Supply Chain and Platform Economy Perspectives (2019), https://ssrn.com/

15. A. Hein, M. Schreieck, T. Riasanow, D. Setzke, M. Wiesche, M. Böhm, H.Krcmar, Electronic Markets, 30(1)

16. Morgane M.C. Fritz, Sustainability Management in Supply Chains: Developing a Supply Chain View to operationalise sustainability among multiple supply chain stakeholders (2017)

17. Digital agenda of the Eurasian Economic Union until 2025. Perspectives and recommendations. World Bank, 30 (2017), http://www.eurasiancommission.org/

18. A.V. Dmitriev, I.A. Plastunyak, Atlantis Highlights in Computer Sciences, 1 (2019)

19. E.S. Rudykh, Digital economy: a course in 2017 (2017), http://files.runet-id.com/ 